IBAD Sosyal Bilimler Dergisi

IBAD Journal of Social Sciences

dergipark.org.tr/ibad

IBAD, 2021; (10): 188-201

DOI: $10.21733 /$ ibad. 871703

Özgün Araştırma / Original Article

\title{
Sosyal Bilimlerde Betimsel İçerik Analizi
}

\section{Descriptive Content Analysis in Social Sciences}

\author{
Eser Ültay ${ }^{*}$ \\ Hakan Akyurt ${ }^{2}$ \\ Neslihan Ültay ${ }^{3}$
}

\begin{abstract}
* Sorumlu yazar
${ }^{1}$ Doç. Dr., Giresun Üniversitesi, Türkiye

Assoc. Prof. Dr., Giresun University, Turkey eserultay@gmail.com

ORCID ID 0000-0001-6839-6361

${ }^{2}$ Doç. Dr., Giresun Üniversitesi, Türkiye Assoc. Prof. Dr., Giresun University, Turkey hakan.akyurt@giresun.edu.tr

ORCID ID 0000-0002-6522-684X

${ }^{3}$ Doç. Dr., Giresun Üniversitesi, Türkiye Assoc. Prof. Dr., Giresun University, Turkey neslihanultay@gmail.com ORCID ID 0000-0002-9783-0486
\end{abstract}

Makale geliş tarihi / First received : 31.01.2021

Makale kabul tarihi / Accepted : 08.03 .2021

\section{Bilgilendirme:}

Yazarlar aşağı daki billgillen dirmeleri yapmaktadırlar:

1- Araştırmacıların katkı oranları eşit düzeydedir.

2- Makalenin yazarları arasında çıkar çatışması bulunmamaktadır.

3- Makalemizde etik kurulu izni ve/veya yasal/özel izin alınmasını gerektiren bir durum yoktur.

4- Bu makalede araştırma ve yayın etiğine uyulmuştur.

This article was checked by Turnitin. Similarity Index 04\%

\section{Atıf bilgisi:}

Ültay, E., Akyurt, H., Ültay, N. (2021). Sosyal bilimlerde betimsel içerik analizi. IBAD Sosyal Bilimler Dergisi, (10), 188201. 
Öz

Betimsel içerik analizi yöntemi, belirli bir konuda ya da alanda birbirinden bağımsız olarak yapılan nitel ve nicel çalışmaların derinlemesine incelenip düzenlenmesi anlamına gelir. Böylece o konu ya da alandaki genel eğilimler belirlenmektedir. Bu yöntemde elde edilen sonuçların, hedeflenen konulara yönelik olarak gelecekte planlanan çalışmalara yön göstermesi beklenmektedir. Bu çalışmanın temel amacl, eğitim bilimleri alanında sıcça kullanılmakta olan betimsel içerik analizi yönteminin, diğer sosyal bilimler alanlarında da kullanılabilmesi için, analizin nasıl yapılacağına dair soruların giderilmesini sağlamaktır. Çalışmanın, sosyal bilimler alanında betimsel içerik analizini kullanmak isteyen akademisyenlere yön göstermesi, temel bir kaynak olması hedeflenmektedir. Betimsel içerik analizinde, özellikle incelenen çalışmaların amaçlarına, gerekçelerine, sonuçlarına ve önerilerine ait analizlerde nitel analiz yaklaşımlarına uygun olarak, kod havuzu oluşturup, bu kodlara uygun temalandırma/kategorilendirme yönteminin kullanılması, betimsel içerik analizi çalışmalarının nitelik açısından da zenginleşmesini sağlayacaktır. Ayrıca, yapılacak olan betimsel içerik analizi çalışmalarında, incelenen çalışmalar, standartlaşmış analiz aşamaları dışında, benzer konulardaki diğer betimsel içerik analizi çalışmalarından ayrılması adına, farklı yönlerden de analize tabi tutulması gerekmektedir.

\section{Anahtar kelimeler}

Analiz türleri, betimsel içerik analizi, sosyal bilimler

\section{ABSTRACT}

Descriptive content analysis method means that qualitative and quantitative studies conducted independently from each other in a particular subject or field are examined and organized in depth. Thus, general trends in that subject or area are determined. The results obtained in this method are expected to guide the planned studies in the future towards the targeted subjects. The main purpose of this study is to solve the questions about how to analyze the descriptive content analysis method, which is frequently used in the field of educational sciences, in order to be used in other social sciences. The study aims to guide academicians who want to use descriptive content analysis in the field of social sciences and to be a basic resource. In the descriptive content analysis, especially in the analysis of the aims, reasons, results and suggestions of the studied studies, creating a code pool in accordance with the qualitative analysis approaches and using the appropriate theming/categorization method will ensure that the descriptive content analysis studies are enriched in terms of quality. In addition, in the descriptive content analysis studies to be carried out, the studied studies should be analyzed from different aspects in order to distinguish them from other descriptive content analysis studies on similar topics, apart from the standardized analysis stages.

\section{Keywords}

Types of analysis, descriptive content analysis, social sciences 


\section{GíRiş}

Bilimsel çalışmalarda, her alanda, farklı analiz türlerinin kullanımı yaygınlaşmıştır. Çalışmaların içeriğini desteklemek ve gelecek çalışmalara yön vermek amacı ile birçok farklı analiz türleri kullanılmıştır. Her bilim alanı kendine uygun analizler ortaya koymakta ve kullanım biçimleri bilim dalına yönelik olarak değişimler göstermektedir. Bu kapsamda özellikle sosyal bilimler alanında kullanılan birbirinden farklı birçok analiz türünden bahsetmek mümkündür. İçerik analizleri de sosyal bilimler alanı içerisinde özellikle eğitim bilimleri çalışmalarında sıklıkla kullanılmaktadır (Loomis, Davis, Cruden, Padilla ve Drazen, 2021; Neuendorf, 2002; Ültay, Dönmez Usta ve Durmuş, 2017; Ültay ve Ültay, 2014). Son yıllarda sosyal bilimlerin diğer alanlarında da içerik analizlerinin kullanıldığı çalışmaların sayılarında da artış görülmektedir (Cleave, Arku ve Chatwin, 2017; López-Bonilla, ReyesRodríguez ve López-Bonilla, 2020). İçerik analizi çalışmalarının genel amacı, ele alınan konu kapsamında, daha sonra yapılacak akademik çalışmalara yol göstermesi ve konu ile ilgili genel eğilimin tespitinin sağlanmasıdır.

İçerik analizleri de kendi içerisinde meta-analiz, meta-sentez (tematik içerik analizi) ve betimsel içerik analizi olarak üç farklı yöntem ile ifade edilmektedir (Çalık ve Sözbilir, 2014). $\mathrm{Bu}$ çalışmada ele alınan konu olan betimsel içerik analizi, belirlenmiş bir konu dahilinde yapılan, yayınlanmış ya da yayınlanmamış, bütün çalışmaların ele alınıp eğilimlerinin ve araştırma sonuçlarının tanımlayıcı bir boyutta değerlendirilmesini içeren sistematik çalışmalardır (Jayarajah, Saat ve Rauf, 2014; Lin, Lin ve Tsai, 2014; Suri ve Clarke, 2009). Başka bir ifadeyle, belirlenmiş bir konu dahilinde, birbirinden bağımsız olarak yapılan, yayınlanmış ya da yayınlanmamış, bütün nitel ve nicel çalışmalar incelenip düzenlenmekte ve alandaki genel eğilimler belirlenmektedir. Böylece, ilgili alanda ve konuda çalışma yapan veya yapmak isteyen araştırmacılara genel eğilimin ne olduğu gösterilmektedir (Cohen, Manion ve Morrison, 2007; Miles ve Huberman, 1994).

$\mathrm{Bu}$ analiz yönteminde elde edilen sonuçların, hedeflenen konulara yönelik olarak gelecekte planlanan çalışmalara yön göstermesi beklenmektedir (Lune ve Berg, 2017; Yıldırım ve Şimşek, 2018). Betimsel içerik analizlerin farklı çalışmalarda kullanılması nedeni ile, sistematik bir şekilde literatürün sunulması zorunluluğu bulunmaktadır. Bu yöntemi kullanan çalışmalarda bu sistematik bilginin sunulmaması halinde, analizin temel amacına uygun olamayan sonuçlar ortaya çıkmaktadır. Betimsel içerik analizinin kullanıldığı çalışmalarda, elde edilen bilgilerin doğru ve sistemli bir şekilde ortaya konulması, analize tabi tutulması, yorumlanması ve sonuçların açık bir şekilde belirtilmesi gerekmektedir.

Bu çalışmanın temel amacı, özellikle eğitim bilimler alanında sıkça kullanılmakta olan betimsel içerik analizi yönteminin, diğer sosyal bilimler alanlarında da, doğru yöntem ve analiz teknikleri ile, kullanılabilmesi için, analizin nasıl yapılacağına dair oluşabilecek sorunların giderilmesini sağlamaktır. Betimsel içerik analizi çalışmaları yürütülürken, kullanılacak olan analiz sorularının net olarak ortaya konulması, verilerin hangi şekilde analiz edileceği ve verilerin yorumlanmasına yönelik sistemli bir yaklaşımın net bir biçimde ortaya konulması gerekmektedir. Bu kapsamda, bu çalışmada, betimsel içerik analizi çalışmalarında uygulanması gereken adımların neler olduğu ortaya konulmaya çalışılarak, verilerin yorumlanmasının nasıl olacağı belirtilmeye çalışılmıştır. Bu çalışmada, betimsel içerik analizini hem eğitim bilimleri alanında hem de diğer tüm sosyal bilimler alanlarında kullanmak isteyen araştırmacıların analizlerini nasıl yapması gerektiğine yönelik bilgiler sunulmaktadır. 
Çalışmanın, sosyal bilimler alanında betimsel içerik analizini kullanmak isteyen akademisyenlere yön göstermesi, temel bir kaynak olması hedeflenmektedir.

\section{Betimsel İçerik Analizi Çalışmalarında İncelenecek Çalışmaların Belirlenme Kriterleri}

Bu bölümde, betimsel içerik analizi çalışmalarında, araştırmaya dahil edilecek çalışmaların belirlenme kriterlerine yer verilmiştir.

Araştırmacılar, ilk olarak hangi konu dahilinde betimsel içerik analizi çalışması yürüteceklerine karar verirler. Daha sonra ilgili konuya ait, literatür taraması yoluyla, araştırmaya dahil edilecek çalışmaların bir havuzu oluşturulur. Literatür taraması, ulusal/uluslararası üniversite kütüphanelerinin veri tabanları ve ulusal/uluslararası tez merkezleri gibi veri tabanlarından detaylı arama kısımları kullanılarak yapılabilir. Veri tabanlarından detaylı arama yapılırken, belirlenen konu dahilinde, anahtar kelimeler kullanılır. Örneğin, "turizm işletmelerinde iş alanları" kapsamında yapılan çalışmaların literatür taraması yapılacaksa, anahtar kelimeler, "turizmde iş" ve/veya "turizm işletmeleri" olabilir. Bu anahtar kelimeler, incelenecek çalışmaların tam metinlerinde aranacağı gibi, ilgisiz çalışmalara ulaşma olasılığını azaltmak için, özetlerinde ve/veya başlıklarında da aranabilir. Bu aşamalardan sonra, elde edilen çalışma sayısı oldukça fazla ise ve analizi güçleşti ise arama kriterlerinde bazı sınırlamalara gidilebilir. Örneğin, sadece üniversite öğrencileri ile yapılan çalışmaların tespiti için örneklem sınırlaması; sadece ulusal çalışmaların tespiti için dil sınırlaması; sadece 2000li yıllardaki çalışmaların tespiti için ise yıl sınırlaması yöntemleri kullanılabilir.

Unutulmamalıdır ki, yapılacak olan betimsel içerik analizi çalışmalarının yöntem kısmında, araştırmaya dahil edilen çalışmaların belirlenme kriterleri (anahtar kelimeler, sınırlılıklar ve veri tabanları) açıkça belirtilmelidir.

\section{Betimsel İçerik Analizi Çalışmalarında Kullanılabilecek Analiz Türleri}

$\mathrm{Bu}$ bölümde, sosyal bilimler alanlarında ait betimsel içerik analizi çalışmalarında, araştırmacıların kullanabileceği analiz türlerine yer verilmiştir.

Aşağıdaki tabloda, betimsel içerik analizi çalışmalarında, incelenen çalışmaların amaçlarına ilişkin verilerin sunulma şekline bir örnek gösterilmiştir.

Tablo 1. Çalışmaların Amaçları

\begin{tabular}{llc}
\hline Amaçlar & Çalışmalar & $f$ \\
\hline Tema/Kategori 1 & Ç1, Ç5, Ç8, Ç10, Ç13, Ç16, Ç17, Ç20, Ç21, Ç26, Ç27 & 11 \\
\hline Tema/Kategori 2 & Ç2, Ç3, Ç9, Ç12, Ç15, Ç19, Ç22, Ç24 & 8 \\
\hline Tema/Kategori 3 & Ç4, Ç6, Ç7, Ç14, Ç18 & 5 \\
\hline Tema/Kategori 4 & Ç11, Ç23, Ç25 & 3 \\
\hline
\end{tabular}

Tabloya göre, incelenen çalışmaların amaçları temalandırılarak/kategorilendirilerek birinci sütunda sergilenmiştir. Nitel analiz yaklaşımlarına göre, temelandırma/kategorilendirme işlemi, zihinsel süreçlerin gerçekleştiği, uzun zaman alan ve farklı zaman ve mekanlarda dikkatle hazırlanması gereken bir süreçtir. Temalandırma/kategorilendirme işlemini yapacak araştırmacıların, çalışmanın inandırıcılığını artırmak adına, tablonun betimlemesi yapıldıktan sonra, incelemeye tabi tuttuğu çalışmaların bazılarının amaç cümlelerini olduğu gibi okuyucu ile paylaşarak hangi temaya/kategoriye dahil edildiğini açıkça belirtmesi gerekmektedir. Yukarıdaki tabloya göre açılamak gerekirse, incelenen 27 çalışmanın amaç cümleleri 
transkript edilir, bu amaç cümlelerine uygun kod havuzu oluşturulur ve bu kodlara uygun olarak da temalar/kategoriler oluşturularak tablonun birinci sütununda sunulur. Temalar/kategoriler bir kelime ya da kelime grubu olabileceği gibi bir ya da birkaç cümleden de oluşabilir. Buradaki amaç, her bir çalışmanın amaç cümlesinin 27 satırda verilerek veri kirliliği oluşturmak yerine, daha az sayıda satırdan oluşan, okunurluğu artıran ve temalardan/kategorilerden oluşan bir tablo oluşturmaktır. Bu süreç araştırmacıları oldukça yoran, ancak bir o kadar da betimsel içerik analizi çalışmalarının niteliğini artıran, bir süreçtir.

Hangi çalışmanın hangi temaya/kategoriye ait olduğunu gösteren sütun, yukarıdaki tabloya göre ikinci sütundur. Tabloda, incelenen çalışmalar, veri kirliliğine neden olmamak adına ve okunurluğu artırmak için Ç1, Ç2, ..., Ç27 şeklinde kodlanarak okuyucuya sunulur. Ancak unutulmamalıdır ki, bu şekilde kodlanan çalışmaların künyeleri, betimsel içerik analizi çalışmalarının kaynakçasında ya da ekinde, açıkça ve kaynakça yazım kurallarına uygun olarak okuyucu ile paylaşılmalıdır.

Üçüncü sütunda ise, hangi temaya/kategoriye ait kaç çalışmanın olduğunu gösteren, frekans bilgisi sunulmuştur. Tablodan da anlaşılacağı gibi frekans değerlerine göre tablo satırlarının sırası oluşturulur. Yani frekansı en yüksek olan tema/kategori en üstte olacak şekilde sıra ile satırlar oluşturulur. Ayrıca aynı frekansa sahip temalar/kategoriler mevcut ise, bu temalar/kategoriler harf sırasına göre sıralanır. Bu sayede, araştırmacılar belirlenen konu dahilinde, yapılmış olan çalışmaların amaç eğilimlerini tespit etmiş ve yapacakları çalışmaya yön vermiş olurlar.

Aşağıda, betimsel içerik analizi çalışmalarında, incelenen çalışmaların gerekçelerine ait verilerin sergilendiği tablo örneği sunulmaktadır.

Tablo 2. Çalışmaların Gerekçeleri

\begin{tabular}{llcc}
\hline Gerekçeler & Çalışmalar & $\boldsymbol{f}$ & \% \\
\hline Tema/Kategori 1 & Ç1, Ç5, Ç8, Ç10, Ç13, Ç16, Ç17, Ç20, Ç21, Ç23, Ç26, Ç27 & 12 & 44,44 \\
\hline Tema/Kategori 2 & Ç3, Ç9, Ç12, Ç15, Ç19, Ç22, Ç24 & 7 & 25,92 \\
\hline Tema/Kategori 3 & Ç2, Ç4, Ç6, Ç7, Ç14, Ç18 & 6 & 22,22 \\
\hline Tema/Kategori 4 & Ç11, Ç25 & 2 & 7,41 \\
\hline
\end{tabular}

Betimsel içerik analizi çalışmalarında, incelenen çalışmaların gerekçelerine ait verilerin sergilendiği tablonun ilk üç sütunu, amaç tablosuna benzer niteliktedir. Temalandırma/kategorilendirme, çalışmaların kodları (Ç1, Ç2, Ç3 ...) ile gösterimi ve frekans bilgileri tıpkı amaç tablosundaki gibi sunulur. Gerekçe tablosunda bunlara ek olarak, incelenen çalışmaların yüzde kaçının hangi temeya/kategoriye ait olduğunu gösteren yüzdelik sütunu da okuyucu ile paylaşılabilir. Bu sayede araştırmacılar belirlenen konu dahilinde, yapılmış olan çalışmaların gerekçe eğilimlerini daha net tespit etme olanağına sahip olurlar ve çalışmalarına bu eğilimlere göre yön verebilirler. Burada dikkat edilmesi gereken nokta, yüzde değerleri verilirken anlamlı numaraların (significant number) kullanımı kurallarıdır. Yani yapılması planlanan betimsel içerik analizi çalışmasının tamamında, eğer kullanılacaksa, ondalıklı sayılarda, virgülden sonra aynı miktarda basamak kullanılması gerekmektedir. Yukarıdaki tablodan örnek verirsek, yüzdelik değerlerinin ondalıklı sayı olarak yazılmasında, virgülden sonra iki basamak kullanılmış. Dolayısıyla yapılacak betimsel içerik analizi çalışmasının tamamında, eğer ondalıklı sayılar kullanılacaksa, virgülden sonra iki basamak kullanılması 
gerekmektedir. Ayrıca şu da belirtilmelidir ki, yüzdelik sütununun amaç tablosunda da kullanılmasında her hangi bir sakınca yoktur.

Aşağıdaki tabloda, betimsel içerik analizine tabi tutulan çalışmaların ne tür çalışmalar olduğunu gösteren verilerin sergilenme biçimine örnek verilmiştir.

Tablo 3. Çalışmaların Türleri (Teorik veya Deneysel)

\begin{tabular}{|c|c|c|c|}
\hline$\#$ & Kronolojik Sıra İle Çalışmalar & Teorik Çalışmalar & Deneysel Çalışmalar \\
\hline 1. & Xxxxx, 1987 & & $\checkmark$ \\
\hline 2. & Yyyyy ve Zzzzz, 1988 & & $\checkmark$ \\
\hline 3. & Aaaaaa ve Bbbbb, 1990 & $\checkmark \quad$ (senaryo tabanlı) & \\
\hline 4. & Cccccc, 1990a & & $\checkmark$ \\
\hline 5. & Cccccc, $1990 \mathrm{~b}$ & $\checkmark$ & \\
\hline 6. & Dddddddd ve Eeeeee, 1993 & & $\checkmark$ \\
\hline 7. & Fffffff ve Ggggggg, 1998 & & $\checkmark$ \\
\hline 8. & Hhhhhh vd., 1999 & & $\checkmark$ \\
\hline 9. & Jjjjjjj vd., 2000 & & $\checkmark$ \\
\hline 10. & Kkkkkk, 2000 & & $\checkmark$ \\
\hline 11. & Ll111111 ve Mmmmmm, 2003 & & $\checkmark$ \\
\hline 12. & Mmmmmm vd., 2003 & $\checkmark$ & \\
\hline 13. & Rrrrrrr, 2005 & & $\checkmark$ \\
\hline 14. & Ttttttt, 2006 & & $\checkmark$ \\
\hline 15. & Uuuuuu ve Aaaaaa, 2006 & $\checkmark \quad$ (senaryo tabanlı) & \\
\hline 16. & Wwwww vd., 2010 & & $\checkmark$ \\
\hline 17. & Eeeee, Ooooo ve Ppppp, 2011 & & $\checkmark$ \\
\hline 18. & Bbbbb, Cccccc ve Qqqqq, 2013 & & $\checkmark$ \\
\hline 19. & Xxxxxx ve Sssss, 2015 & $\checkmark$ & \\
\hline 20. & Ddddddd, 2016 & & $\checkmark$ \\
\hline 21. & Hhhhhh ve Yyyyyy, 2017 & & $\checkmark$ \\
\hline 22. & Kkkkkk, 2018. & & $\checkmark$ \\
\hline 23. & Vvvvvv ve Mmmmm, 2018 & & $\checkmark$ \\
\hline 24. & Eeeeee, 2019 & $\checkmark$ & \\
\hline 25. & Ssssss ve Ppppp, 2020 & & $\checkmark$ \\
\hline 26. & Yyyyyy, 2020 & $\checkmark$ & \\
\hline 27. & Bbbbb ve Rrrrrr, 2021 & & $\checkmark$ \\
\hline
\end{tabular}

Tablonun ilk sütunu, betimsel içerik analizine tabi tutulan çalışma sayısını belirten numaralandırma sütunudur. İkinci sütun, kronolojik olarak sıralanmış ve metin içi kaynak yazma kurallarına uygun olarak verilmiş, incelenen çalışmaların her birini tek tek gösteren sütundur. Burada dikkat edilmesi gereken nokta, aynı yıla ait çalışmalar alfabetik olarak; aynı yaza(lar)a ait aynı yıldaki çalışmalar da yıl bilgisinin yanına “a, b, c, ..." harfleri konularak sıralanmalıdır. Üçüncü ve dördüncü sütunlar ise incelenen çalışmaların ne tür çalışmalar olduğunu gösteren verileri içerir. Teorik ve deneysel olarak sinıflandırılabilir ve teorik olanların da hangilerinin senaryo tabanlı olduğu parantez içinde, tabloda da görüleceği üzere, verilebilir. Bu tablo sayesinde, belirlenen konu dahilinde, çalışmalarına yön verecek olan araştırmacılar, literatürdeki çalışmaların türlerine göre eğilimlerini belirleyebilirler.

Aşağıdaki tabloda, betimsel içerik analizine tabi tutulan çalışmaların metodolojilerine ilişkin verilerin sergilenme biçimine örnek verilmiştir. 
Tablo 4. Çalışmaların Metodolojileri

\begin{tabular}{llll}
\hline \multirow{2}{*}{ Metodolojiler } & Çalışmalar & $f$ \\
\hline \multirow{2}{*}{ Nicel } & Tarama & Ç1, Ç5, Ç10, Ç13, Ç16 & 5 \\
\cline { 2 - 4 } & Karşılaştırmalı Çalışmalar & Ç2, Ç3, Ç9, Ç18 & 4 \\
\hline \multirow{4}{*}{ Nitel } & Etnografik Çalışmalar & Ç19, Ç22, Ç24 & 3 \\
\cline { 2 - 4 } & Didaktik Mühendislik & Ç12, Ç15 & 2 \\
\cline { 2 - 4 } & Eylem Araştırması & Ç4, Ç26 & 2 \\
\cline { 2 - 4 } & Fenomenografik Araştırma & Ç6, Ç7 & 2 \\
\cline { 2 - 4 } & Tarihsel Araştırmalar & Ç17, Ç20 & 2 \\
\hline Durum Çalışması & Ç11, Ç23 & 2 \\
\hline Gelişimsel Araştırma & Ç8, Ç14 & 1 \\
\hline Deneysel Çalısmalar & Ç21 & 1 \\
\hline Dökuman Analizi Araştırması & Ç25 & 2 \\
\hline Ex Post Facto Araştırmaları & Ç27 & 2 \\
\hline
\end{tabular}

Betimsel içerik analizine tabi tutulan çalışmaların metodolojilerinin sergilendiği tabloya göre ilk sütunda, çalışmalarda kullanılan araştırma yöntemleri sergilenmiştir. Tabloda verilen araştırma yöntemleri literatürde yer alan araştırma yöntemleri olduğu için, araştırmacıların bu tabloyu oluştururken kod havuzu oluşturma ve temalandırma/kategorilendirme işlem süreçlerini gerçekleştirmelerine gerek yoktur. Dolayısıyla hazır temalardan/kategorilerden oluşan bu sütun literatürde yer alan araştırma yöntemlerinden oluşur. İncelenen çalışmalar, kodları ve frekansları ile, ikinci ve üçüncü sütunlarda sergilenir. Frekans değerlerine göre sıralanan satırlar, aynı frekansa sahip araştırma yöntemleri harf sırasına göre satır sırasında yer bulur. $\mathrm{Bu}$ tablo sayesinde araştırmacılar, belirlenen konu dahilinde yapılmış olan çalışmaların metodolojik eğilimlerini belirlemiş olurlar ve çalışmalarını yönlendirme konusunda bu tabloyu rehber olarak kullanabilirler.

Aşağıdaki tabloda, betimsel içerik analizine tabi tutulan çalışmaların veri toplama metotlarına ait verilerin sergilenmesine yönelik bir örnek verilmiştir.

Tablo 5. Çalışmaların Veri Toplama Metotları

\begin{tabular}{|c|c|c|c|c|c|c|c|c|c|c|c|}
\hline \multirow[b]{4}{*}{$\begin{array}{l}\text { Kronolojik Sıra İle } \\
\text { Çalışmalar }\end{array}$} & \multicolumn{6}{|c|}{ Veri Toplama Araçları } & \multicolumn{5}{|c|}{ Uygulama } \\
\hline & \multirow[b]{3}{*}{$\mathbf{M}$} & \multirow[b]{3}{*}{ G } & \multirow[b]{3}{*}{$\mathbf{P}$} & \multirow{2}{*}{\multicolumn{3}{|c|}{$\begin{array}{r}\text { KKA } \\
\mathbf{A}\end{array}$}} & \multirow[b]{3}{*}{$\begin{array}{c}\text { Örneklem Sayısı } \\
\text { ve Grubu }\end{array}$} & \multirow{2}{*}{\multicolumn{4}{|c|}{$\begin{array}{c}\text { Örneklem } \\
\text { Seçimi }\end{array}$}} \\
\hline & & & & & & & & & & & \\
\hline & & & & AUS & LTS & ÇSS & &  & 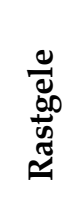 & 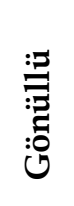 & 苛 \\
\hline Xxxxx, 1987 & & & & & & $\checkmark$ & 105 öğrenci & & & & $\checkmark$ \\
\hline Yyyyy ve Zzzzz, 1988 & & & & $\checkmark$ & $\checkmark$ & $\checkmark$ & 455 öğrenci & $\checkmark$ & & & \\
\hline Cсcссс, 1990a & & $\checkmark$ & & & $\checkmark$ & & 100 fen öğretmeni & & $\checkmark$ & & \\
\hline $\begin{array}{l}\text { Dddddddd ve Eeeeee, } \\
1993\end{array}$ & $\checkmark$ & & & $\checkmark$ & & $\checkmark$ & $\begin{array}{lrr}42 & 10 . & \text { sinıf } \\
\text { öğrencisi } & \end{array}$ & & & $\checkmark$ & \\
\hline $\begin{array}{l}\text { Fffffff ve Ggggggg, } \\
1998\end{array}$ & $\checkmark$ & & & & $\checkmark$ & $\checkmark$ & 50 öğretmen & & $\checkmark$ & & \\
\hline Hhhhhh vd., 1999 & $\checkmark$ & & & & & & Bir öğretmen & $\checkmark$ & & & \\
\hline Jjjjijj vd., 2000 & $\checkmark$ & $\checkmark$ & & $\checkmark$ & & & 220 öğrenci & & & $\checkmark$ & \\
\hline
\end{tabular}




\begin{tabular}{|c|c|c|c|c|c|c|c|c|c|c|}
\hline Kkkkkk, 2000 & $\checkmark$ & $\checkmark$ & & & & $\checkmark$ & 9 akademisyen & & & $\checkmark$ \\
\hline $\begin{array}{l}\text { L1ll1lll ve Mmmmmm, } \\
2003\end{array}$ & & & & & $\checkmark$ & & $\begin{array}{l}1546 \quad \text { üniversite } \\
\text { öğrencisi }\end{array}$ & $\checkmark$ & & \\
\hline Rrrrrrr, 2005 & $\checkmark$ & & & & $\checkmark$ & & 99 öğrenci & & $\checkmark$ & \\
\hline Ttttttt, 2006 & & & & $\checkmark$ & & $\checkmark$ & 25 öğretmen & $\checkmark$ & & \\
\hline Wwwww vd., 2010 & $\checkmark$ & & $\checkmark$ & & $\checkmark$ & & 200 öğrenci & & $\checkmark$ & \\
\hline $\begin{array}{l}\text { Eeeee, Ooooo ve } \\
\text { Ppppp, } 2011\end{array}$ & $\checkmark$ & $\checkmark$ & & & & & 6 kişi & & & $\checkmark$ \\
\hline $\begin{array}{l}\text { Bbbbb, Cccccc ve } \\
\text { Qqqqq, } 2013\end{array}$ & & & & $\checkmark$ & & & 112 öğrenci & & & $\checkmark$ \\
\hline Ddddddd, 2016 & $\checkmark$ & $\checkmark$ & & & & $\checkmark$ & 22 turizm eğitmeni & & $\checkmark$ & \\
\hline $\begin{array}{l}\text { Hhhhhh ve Yyyyyy, } \\
2017\end{array}$ & & $\checkmark$ & & & $\checkmark$ & & 20 sanat öğretmeni & & & $\checkmark$ \\
\hline Kkkkkk, 2018. & & & & $\checkmark$ & & & 15 öğretmen & & & $\checkmark$ \\
\hline $\begin{array}{l}\text { Vvvvvv ve Mmmmm, } \\
2018\end{array}$ & $\checkmark$ & $\checkmark$ & & & $\checkmark$ & $\checkmark$ & $\begin{array}{l}88 \text { 9. sinıf öğrencisi } \\
\text { ve } 5 \text { öğretmen }\end{array}$ & & $\checkmark$ & \\
\hline Ssssss ve Ppppp, 2020 & $\checkmark$ & & & & $\checkmark$ & & 45 öğrenci & $\checkmark$ & & \\
\hline Bbbbb ve Rrrrrr, 2021 & & $\checkmark$ & & $\checkmark$ & & $\checkmark$ & 28 öğrenci & & & $\checkmark$ \\
\hline
\end{tabular}

Üstteki tabloya göre, ilk sütunda, betimsel içerik analizine dahil edilen deneysel çalışmaların tamamı kronolojik olarak sıralanmış ve metin içi kaynak yazma kurallarına uygun olarak verilmiştir. Diğer sütunlarda ise, bu çalışmalarda kullanılan veri toplama araçları ve deneysel süreçlerde kullanılan örneklem sayısı ve grubuyla, bu örneklem grubunun seçilme kriterlerine yer verilmiştir. Ayrıca, tablo betimlendikten sonra, incelenen bazı çalışmaların örneklem grubu seçim kriterleri (amaçlı, rastgele ya da gönüllü) ile ilgili bilgilerin, inandırıcılığı artırmak için okuyucu ile paylaşılması uygun olacaktır. Tablodan da anlaşılacağı üzere, veri kirliliğine sebep olmaması ve okunurluğu artırmak adına bazı kısaltmalara yer verilebilir. Ancak unutulmaması gereken nokta, bu kısaltmaların ne anlama geldiği mutlaka tablo altında bilgilendirme amacıyla okuyucu ile paylaşılmalıdır. Bu tabloyu inceleyen araştırmacılar, belirlenen konu dahilinde, hangi veri toplama araçlarının ve hangi örneklem gruplarının araştırmalarda kullanıldığını açıkça ve kolayca tespit edebilmekte, belirlenen konuya ait veri toplama metot eğilimlerini görebilmektedirler. Bu yolla araştırmacıların kendi çalışmalarında kullanmaları gereken veri toplama araçlarını ve örneklem grubunu tespit etmesi kolaylaşacaktır.

Aşağıdaki iki grafikte, betimsel içerik analizine tabi tutulan araştırmaların veri toplama araçlarına ve örneklem grubuna vurgu yapmak için, veri toplama araçları dağılımı ve örneklem grubu dağılımı grafikleri üstteki tablo kullanılmaksızın ayrıca içerik analizi çalışmalarında sunulabilir. 
Grafik 1. Çalışmaların Veri Toplama Araçları Dă̆̆lımı

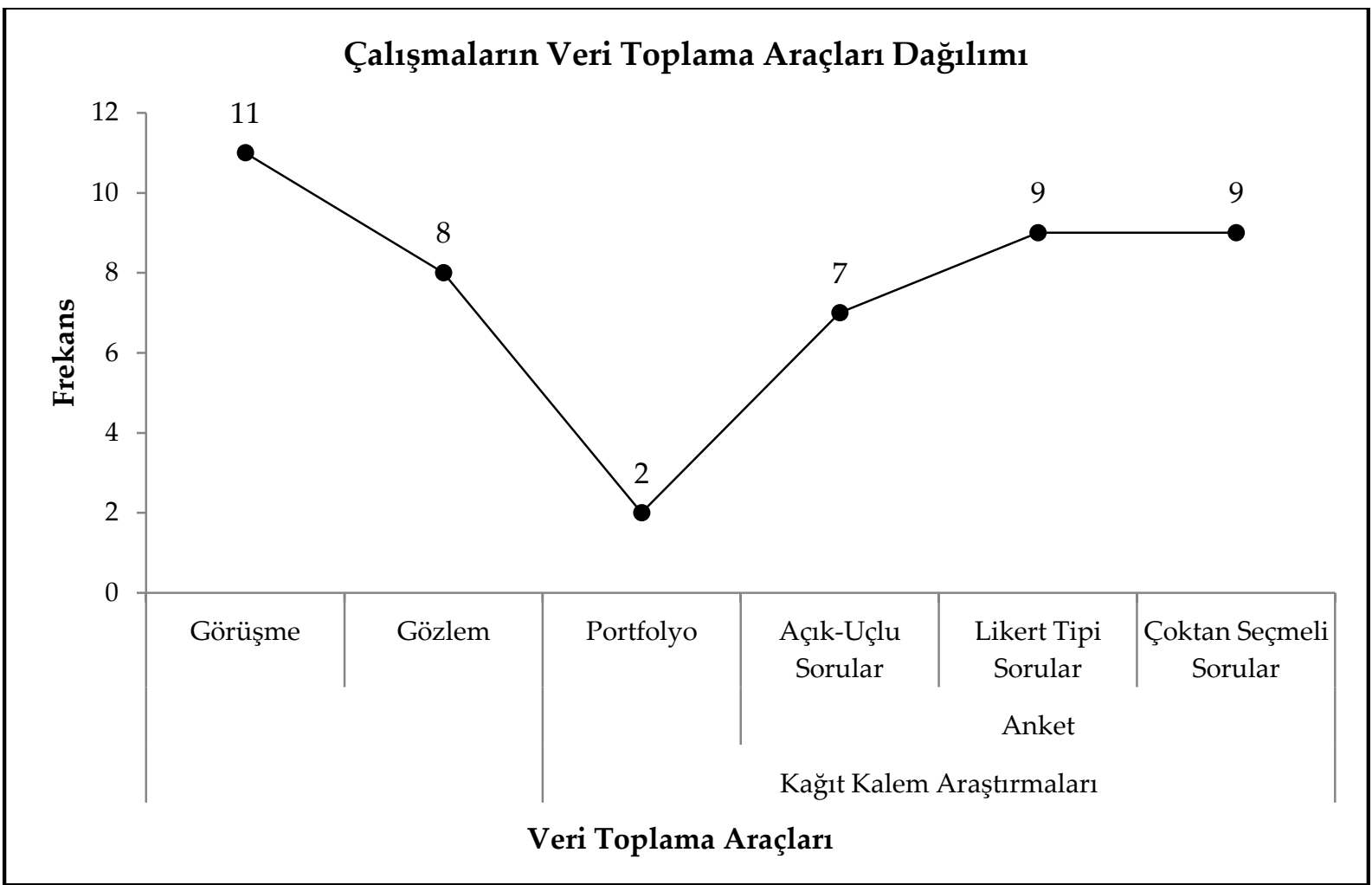

Grafik 2. Çalışmaların Örneklem Dă̆glımı

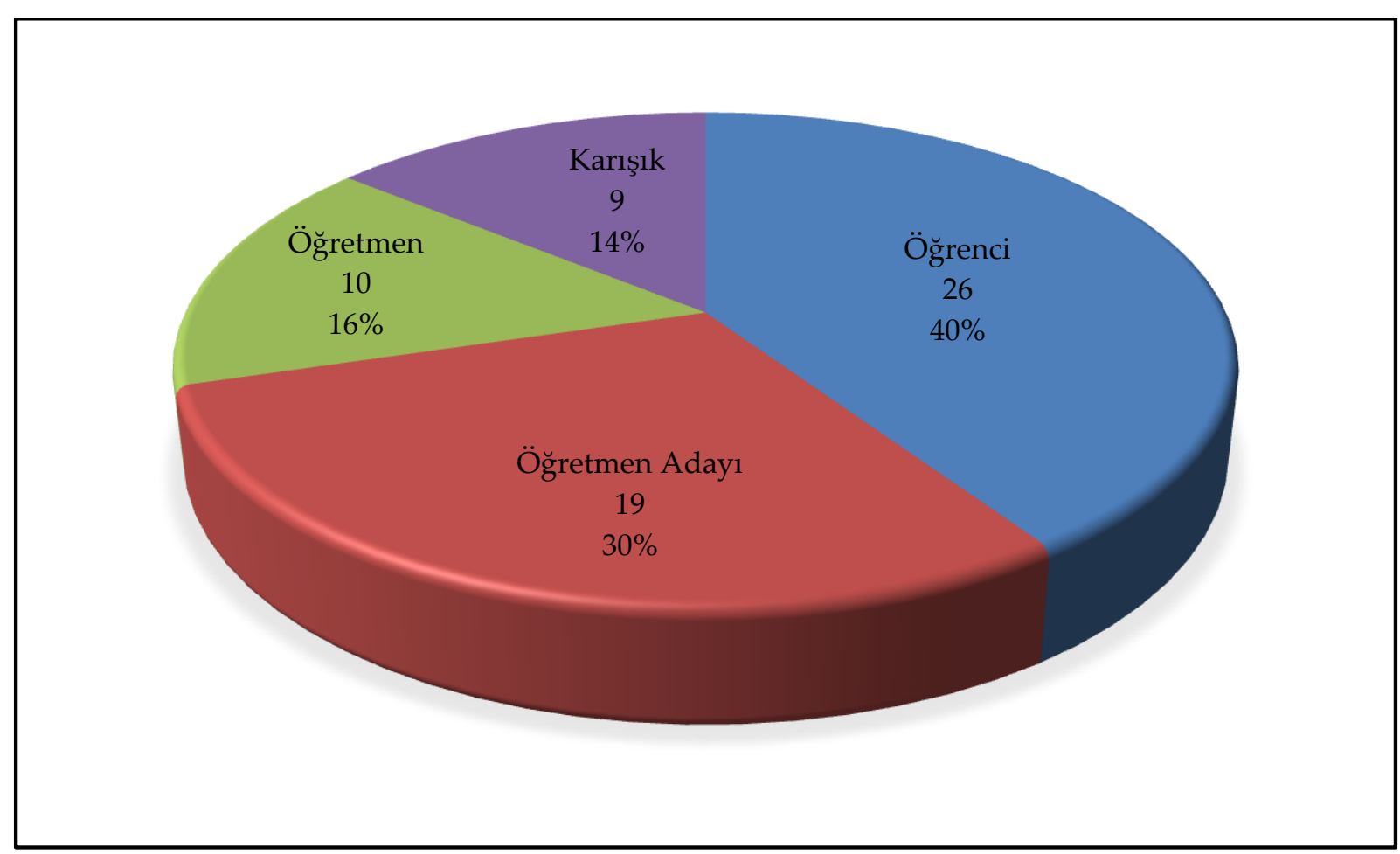

Veri toplama metot tablosundan bağımsız olarak, içerik analizi çalışmalarında, özellikle veri toplama araçları ve örneklem grubuna dikkat çekmek isteyen araştırmacılar, görsel açıdan daha etkili olan üstteki çizgi ve pasta grafiklerine de çalışmalarında yer verebilirler. Bu 
grafikler sayesinde araştırmacılar, belirlenen konu dahilinde, çalışmaların veri toplama araçları ve örneklem grubu eğilimlerine kolayca ulaşabilir ve çalışmalarına yön verebilirler.

Aşağıda betimsel içerik analizine dahil edilen çalışmaların, çalışma alanları dağılımı örnek bir sütun grafiği ile verilmiştir.

Grafik 3. Çalışmaların Konu Alanları

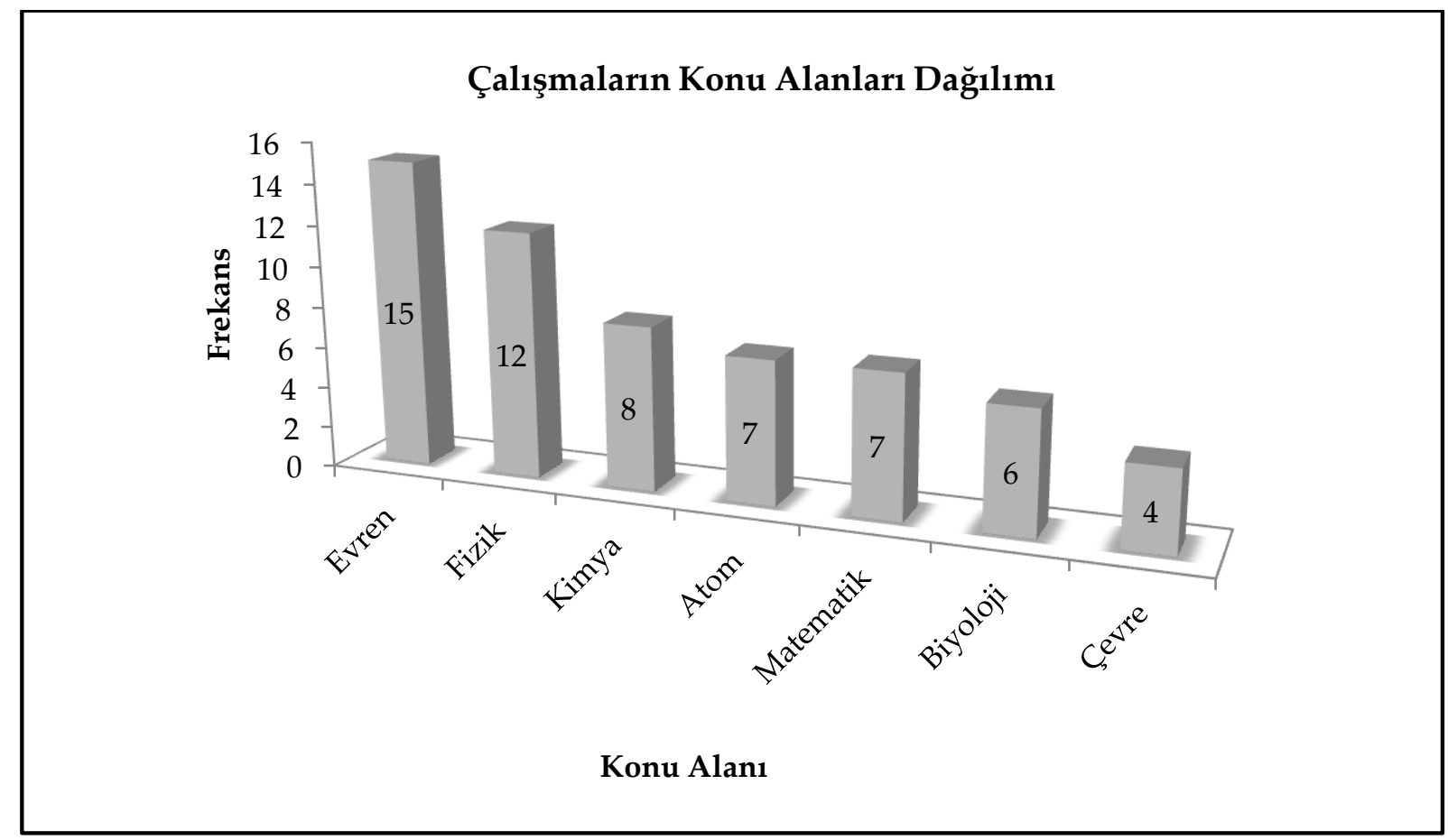

Üstteki sütun grafiğinde, betimsel içerik analizi çalışmasına dahil edilen araştırmaların, çalışma alanları gösterilmiştir. Görsel açıdan etkili olan bu grafikle araştırmacılar, belirlenen konu dahilinde, hangi çalışma alanlarının hangi sıklıkla kullanıldığ ve yapacakları araştırmalarda kullanmak istedikleri çalışma alanlarını bu verilere göre şekillendirebilirler. Grafik, frekansı yüksek olandan az olana göre sıralanırsa araştırma alanları eğilimi daha net ortaya çıkacaktır. Ayrıca unutulmamalıdır ki, yukarıdaki üç grafik, tabloya dönüştürülerek de okuyucu ile paylaşılabilir. Bu grafiklerin kullanılma amacı, grafiklerin görsel etkisinden faydalanmaktır.

Aşağıdaki tablo, betimsel içerik analizine tabi tutulan çalışmaların bulgu, sonuç ve önerilerine ait verilerin sergilenmesine örnek olarak verilmiştir.

Tablo 6. Çalışmaların Bulguları, Sonuçları ve Önerileri

\begin{tabular}{llll}
\hline Kronolojik Sıra İle Çalışmalar & Bulgular & Sonuçlar & Öneriler \\
\hline Xxxxx, 1987 & $\begin{array}{l}\text { En önemli bulgu } \\
\text { buraya yazılır. }\end{array}$ & $\begin{array}{l}\text { En önemli sonuç } \\
\text { buraya yazılır. }\end{array}$ & $\begin{array}{l}\text { Sonuçlara uygun } \\
\text { öneri buraya yazıllır. }\end{array}$ \\
\hline Yyyyy ve Zzzzz, 1988 & $\begin{array}{l}\text { En önemli bulgu } \\
\text { buraya yazılır. }\end{array}$ & $\begin{array}{l}\text { En önemli sonuç } \\
\text { buraya yazılır. }\end{array}$ & $\ldots$ \\
\hline Cccccc, 1990a & $\begin{array}{l}\text { En önemli bulgu } \\
\text { buraya yazılır. }\end{array}$ & $\ldots$ & $\ldots$ \\
\hline Ddddd, 1993 & $\ldots$ & $\ldots$ & $\ldots$ \\
\hline$\ldots$ & $\ldots$ & $\ldots$ & $\ldots$ \\
\hline
\end{tabular}


Tabloya göre, betimsel içerik analizi çalışmasında kullanılan çalışmalar birinci sütunda kronolojik olarak sıralanıp sergilenmiştir. İkinci sütunda bulgular, üçüncü sütunda sonuçlar ve dördüncü sütunda ise önerilere yer verilebilir. Bu tablo oluşturulurken veri kalabalığını önlemek adına, bulgular sütununa çalışmaların en önemli bulgusu, sonuçlar sütununa en önemli araştırma sonucu ve öneriler sütununa ise elde edilen en önemli sonuca bağlı olarak yapılan öneriye yer verilmelidir. Bu tablo oluşturulurken bütün çalışmalara ayrı ayrı yer verilmesi ve çok sayıda satır kullanımına ve veri kirliliğine bağlı olarak okunurluğu bozacağ unutulmamalıdır. Bu sebeple, betimsel içerik analizine tabi tutulan çalışmaların bulguları, sonuçları ve önerileri ayrı ayrı tablolaştırılarak, tıpkı amaç ve gerekçe tablolarındaki süreçler işletilmek koşulu ile okuyucuyla paylaşılması tavsiye edilir. Bu yolla araştırmacılar, belirlenen konu dahilinde, bulgu, sonuç ve öneriler eğilimlerini daha rahat tespit edebilirler.

Aşağıda, betimsel içerik analizine tabi tutulan çalışmalarda alınan güvenirlik önlemleri verilerinin sergilenmesine örnek bir tablo verilmiştir. Bu tablo, betimsel içerik analizi çalışmalarına dahil edilen çalışmaların standart analiz türlerinden farklı bir yönünün sergilenmesi açısından önem taşımaktadır.

Tablo 7. Çalışmalarda Alınan Güvenirlik Önlemleri

\begin{tabular}{lll}
\hline Güvenirlik Önlemleri & Çalışmalar & $f$ \\
\hline Uzman görüşlerinin alınması & Ç1, Ç5, Ç8, Ç10, Ç13, Ç16, Ç17, Ç20, Ç21, Ç26, Ç27 & 11 \\
\hline Pilot uygulamalarının yapılması & Ç2, Ç3, Ç4, Ç7, Ç9, Ç12, Ç15, Ç19, Ç22, Ç24 & 10 \\
\hline Üçgenleme tekniğinin kullanılması & Ç4, Ç6, Ç7, Ç14, Ç18, Ç20, Ç21, Ç26 & 8 \\
\hline Uzun süreli katılımın gerçekleştirilmesi & Ç5, Ç8, Ç10, Ç11, Ç23, Ç25 & 6 \\
\hline Katılımc1 teyidinin sağlanması & Ç7, Ç9, Ç12, Ç15, Ç19 & 5 \\
\hline Gönüllügüü esas alınması & Ç5, Ç8, Ç10, Ç13 & 4 \\
\hline $\begin{array}{l}\text { SPSS gibi paket programlarla } \\
\text { güvenirlik analizlerinin yapılması }\end{array}$ & Ç17, Ç20, Ç21, Ç26 & 4 \\
\hline Okuyucu güvenirliğinin sağlanması & Ç20, Ç21, Ç26 & 3 \\
\hline $\begin{array}{l}\text { Etik ve veri gizliliği konularında } \\
\text { bilgilendirmelerin yapılması }\end{array}$ & Ç2, Ç3, Ç4 & 3 \\
\hline $\begin{array}{l}\text { Katılımciların alışık oldukları doğal } \\
\text { ortamlarında verilerin toplanması }\end{array}$ & Ç23, Ç25 & 2 \\
\hline Katılımcı gözlemci kullanımı & Ç5 & 1 \\
\hline $\begin{array}{l}\text { Verinin doğasına bağl1 kalınarak ham } \\
\text { verilere yer verilmesi }\end{array}$ & Ç27 & 1 \\
\hline
\end{tabular}

Yukarıdaki tabloda ilk sütun, içerik analizinde incelenen çalışmalarda alınan güvenirlik önlemlerini göstermektedir. Bu önlemler yine literatürde yer alan önlemler olduğundan, hazır temalar/kategoriler kullanılabilir. Unutulmamalıdır ki, akademik çalışmaların özgün olması çok önemlidir. Betimsel içerik analizi çalışmalarının da özgün değere sahip olması için yapılacak içerik analizi çalışmalarının, diğer çalışmalarından ayıran, farklı yönlerinin de analizinin yapılması gerekmektedir. Bu sebeple, analizi yapılan çalışmalarda alınan güvenirlik önlemleri analizi gibi, incelenecek çalışmaların farklı yönlerinin analizinin yapılması ve çalışmaya dahil edilmesi betimsel içerik analizi çalışmalarının özgün değerini artıracaktır. 


\section{SONUÇ ve ÖNERILER}

Sosyal bilimlerde yapılmış betimsel içerik analizi çalışmalarının birçoğunda (Albayrak ve Ciltaş, 2017; Buboltz, Miller ve Williams, 1999; Değirmençay ve Cin, 2016; Erdem ve Gezen, 2014; İnce, Gül ve Bozyiğit, 2017; Potter ve Riddle, 2007; Telli Danışmaz, 2019), zihinsel süreçler yürütülmeden gerçekleştirilmiş analizlerle karşılaşılmaktadır. Bu analizler daha çok mevcut durumu sergileyen frekans (sıklık) ve/veya yüzdelik oranlarla sunulmuştur. Özellikle incelenen çalışmaların amaçlarına, gerekçelerine, sonuçlarına ve önerilerine ait analizlerde nitel analiz yaklaşımlarına uygun olarak, kod havuzu oluşturup, bu kodlara uygun temalandırma/kategorilendirme yönteminin kullanılması, betimsel içerik analizi çalışmalarının nitelik açısından da zenginleşmesini sağlayacaktır. Buradan yola çıkarak, sosyal bilimler alanında betimsel içerik analizini kullanmak isteyen akademisyenlerin ve araştırmacıların nitel analiz yaklaşımlarına uygun olarak temalandırma/kategorilendirme yöntemlerini de kullanmaları önerilmektedir.

Ayrıca, yapılmış olan akademik bir çalışmanın özgün değerinin olması gerekmektedir (Fisher ve Anushko, 2012). Bu bağlamda, yapılacak olan betimsel içerik analizi çalışmalarında, incelenen çalışmalar, standartlaşmış (amaç, yöntem, veri toplama araçları, örneklem, sonuç gibi) analiz aşamaları dışında, benzer konulardaki diğer betimsel içerik analizi çalışmalarından ayrılması adına, farklı yönlerden de analize tabi tutulması gerekmektedir. Betimsel içerik analizi çalışması yürütecek araştırmacı ve akademisyenlerin, çalışmalarının özgünlüğüne katkı sağlamaları adına, standartlaşmış analiz aşamaları dışında, elde ettikleri verileri farklı yönlerden de analize tabi tutmaları önerilmektedir.

\section{KAYNAKÇA}

Albayrak, E. ve Ciltaş, A. (2017). Descriptive content analysis of mathematical modeling research published in the field of mathematics education in Turkey. International Journal of Turkish Education Sciences, 5(9), 258-283.

Buboltz, W. C., Miller, M. ve Williams, D. J. (1999). Content analysis of research in the journal of counseling psychology (1973-1998). Journal of Counseling Psychology, 46(4), 496-503.

Cleave, E., Arku, G. ve Chatwin, M. (2017). Cities' economic development efforts in a changing global economy: Content analysis of economic development plans in Ontario, Canada. Area, 49(3), 359-368.

Cohen, L., Manion, L. ve Morrison, K. (2007). Research methods in education. (6 ${ }^{\text {th }}$ Edition). New York: Routledge. 
Çalık, M. ve Sözbilir, M. (2014). Parameters of content analysis. Education and Science, 39(174), 33-38.

Değirmençay, Ş. A. ve Cin, M. (2016). Earthquake education researches in Turkey: A descriptive content analysis. YYU Journal of Education Faculty, 13(1), 301-313.

Erdem, B. ve Gezen, T. (2014). The examination of job advertisements for tourism establishments by content analysis method. Int. Journal of Management Economics and Business, 10(21), 19-42.

Fisher, C. B. ve Anushko, A. E. (2012). Research ethics in social science. London: SAGE Publications.

İnce, M., Gül, H. ve Bozyiğit, S. (2017). Investigation of graduate thesis on tourism marketing in Turkey by content analysis method: 1990-2016. MANAS Journal of Social Studies, 6(5), 113-130.

Jayarajah, K., Saat, R. M. ve Rauf, R. A. A. (2014). A review of science, technology, engineering \& mathematics (STEM) education research from 1999-2013: A Malaysian perspective. Eurasia Journal of Mathematics, Science \& Technology Education, 10(3), 155-163.

Lin, T. C., Lin, T. J. ve Tsai, C. C. (2014). Research trends in science education from 2008 to 2012: A systematic content analysis of publications in selected journals. International Journal of Science Education, 36(8), 1346-1372.

Miles, M. B. ve Huberman, A. M. (1994). Qualitative data analysis. (2 ${ }^{\text {nd }}$ Edition). California: Sage Publications.

Neuendorf, K. A. (2002). The content analysis guidebook. Thousand Oaks, CA: Sage.

Loomis, A., Davis, A., Cruden, G., Padilla, C. ve Drazen, Y. (2021). Early childhood suspension and expulsion: A content analysis of state legislation. Early Childhood Education Journal. https://doi.org/10.1007/s10643-021-01159-4.

López-Bonilla, L. M., Reyes-Rodríguez, M. C. ve López-Bonilla, J. M. (2020). Golf tourism and sustainability: Content analysis and directions for future research. Sustainability, 12, 1-18.

Lune, H. ve Berg, B. L. (2017). Qualitative research methods for the social sciences. (9 ${ }^{\text {th }}$ Edition). England, Essex: Pearson.

Potter, W. J. ve Riddle, K. (2007). A content analysis of the media effects literature. Journalism $\mathcal{E}$ Mass Communication Ouarterly, 84(1), 90-104.

Suri, H. ve Clarke, D. (2009). Advancements in research systhesis methods: From a methodologically inclusive perspective. Review of Educational Research, 79(1), 395-430.

Telli Danışmaz, A. (2019). A descriptive content analysis of researches in social sciences that examine presenteeism. The Journal of International Social Research, 12(65), 1277-1283. 
Ültay, E., Dönmez Usta, N. ve Durmuş, T. (2017). Descriptive content analysis of mental model studies in education. Education for Life, 31(1), 21-40.

Ültay, E. ve Ültay, N. (2014). Context-based physics studies: A thematic review of the literature. Hacettepe University Journal of Education, 29(3), 197-219.

Yildırım, A. ve Şimşek, H. (2018). Qualitative research methods in the social sciences. (11 ${ }^{\text {th }}$ Edition). Ankara: Seçkin. 